\title{
Efficient Persistent Luminescence Tuning Using a Cyclodextrin Inclusion Complex as Efficient Light Conversion Materials
}

\author{
Dan Zhao, Lijun Song, , and Linxi Hou*
}

Cite This: ACS Omega 2021, 6, 25585-25593

Read Online

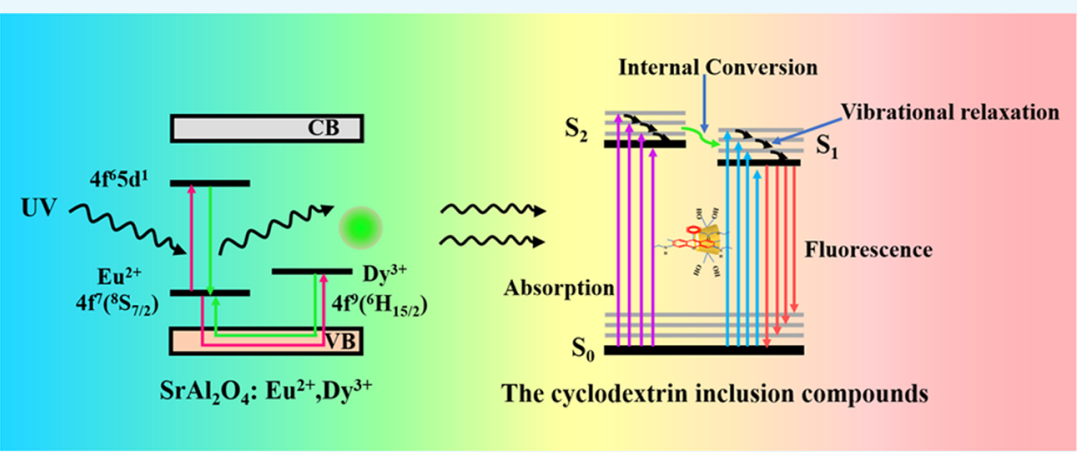

ABSTRACT: Developing an appropriate method to broaden the color of long persistent luminescence materials has important scientific significance and practical value but remains a great challenge. Herein, we have developed a unique strategy to fine-tune the persistent luminescence using the inclusion complex of rhodamine $6 \mathrm{G}$ with (2-hydroxypropyl)- $\beta$-cyclodextrin as efficient light conversion materials. The emitting color of the novel persistent luminescence material could be tuned from green to orange by changing the concentration of the light conversion agent. Furthermore, afterglow decay measurements showed that the initial afterglow brightness is $9.65 \mathrm{~cd} / \mathrm{m}^{2}$, and the initial afterglow brightness gradually decreased as the cyclodextrin inclusion compound coating increased. This design concept introduces a new perspective for broadening the luminescence color of afterglow phosphors, which may open up new opportunities for persistent luminescence materials toward many emerging applications.

\section{INTRODUCTION}

Persistent luminescence, also known as long-lasting phosphorescence or afterglow, is a special optical phenomenon characterized by the ability of some materials to emit light even after the cessation of external light stimulations. ${ }^{1}$ In 1996, Matsuzawa et al. reported for the first time an ultralong green phosphor $\mathrm{SrAl}_{2} \mathrm{O}_{4}: \mathrm{Eu}^{2+}, \mathrm{Dy}^{3+}(\mathrm{SAOED})$ with $30 \mathrm{~h}$ afterglow lifetime. ${ }^{2}$ This pioneering work has prompted the rapid development of persistent luminescence materials in the past few decades. Long persistent luminescence (LPL) materials have a wide range of applications, ${ }^{3-6}$ such as low light illumination and decorative indicators due to their unique optical properties. ${ }^{7}$ Although, blue and green luminescent materials have excellent performance, ${ }^{8-11}$ other colors developed in the laboratory are still in the research stage due to their poor performance. Based on the requirement for trichromatic materials, developing an appropriate method to broaden the luminescence color of the LPL has important scientific significance and practical value but remains a challenge.

In recent years, researchers have conducted in-depth research on the color properties of LPL. ${ }^{12-15}$ For example, Gong et al. realized the light color conversion by spinning the
$\mathrm{CsPbX}$ perovskite quantum dots with strong absorption and high fluorescence quantum yield as an efficient light conversion layer on the surface of a $\mathrm{CaAl}_{2} \mathrm{O}_{4}: \mathrm{Eu}^{2+}, \mathrm{Nd}^{3+}(\mathrm{CAO})$ afterglow phosphor. ${ }^{16}$ Since the preparation method is spin coating, the application in many scenarios is restricted. Zhu et al. prepared a new luminous material $\mathrm{SrAl}_{2} \mathrm{O}_{4}: \mathrm{Eu}^{2+}, \mathrm{Dy}^{3+} /$ light conversion by combining light conversion agent with $\mathrm{SrAl}_{2} \mathrm{O}_{4}: \mathrm{Eu}^{2+}, \mathrm{Dy}^{3+}$, whereas the composite material emits faint red light in the darkness after it excited. ${ }^{17}$ Chen et al. selected TEOS as silicon coating regent to form the $\mathrm{SiO}_{2}$ layer and encapsulated the SAOED phosphor particles and a coumarin-type fluorescent pigment via the sol-gel process. ${ }^{18}$ The blue-green light of SAOED is converted into red light due to the energy transfer from SAOED to light conversion agent, but the afterglow duration and luminous brightness are seriously reduced due to the influence of the coating layer.

Received: July 12, 2021

Accepted: September 9, 2021

Published: September 20, 2021 


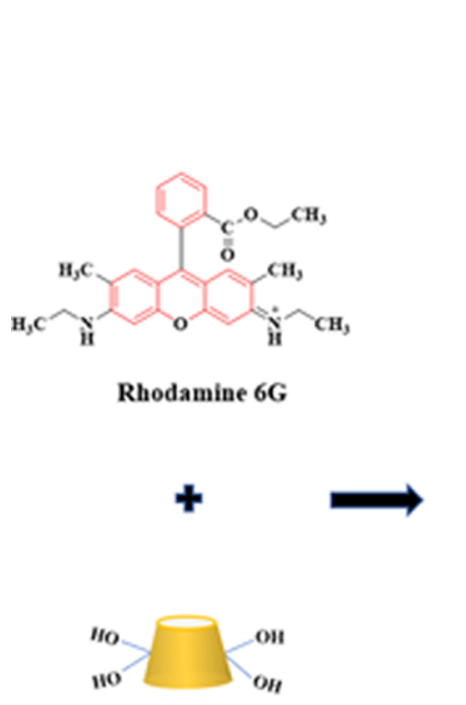

HP- - -CD
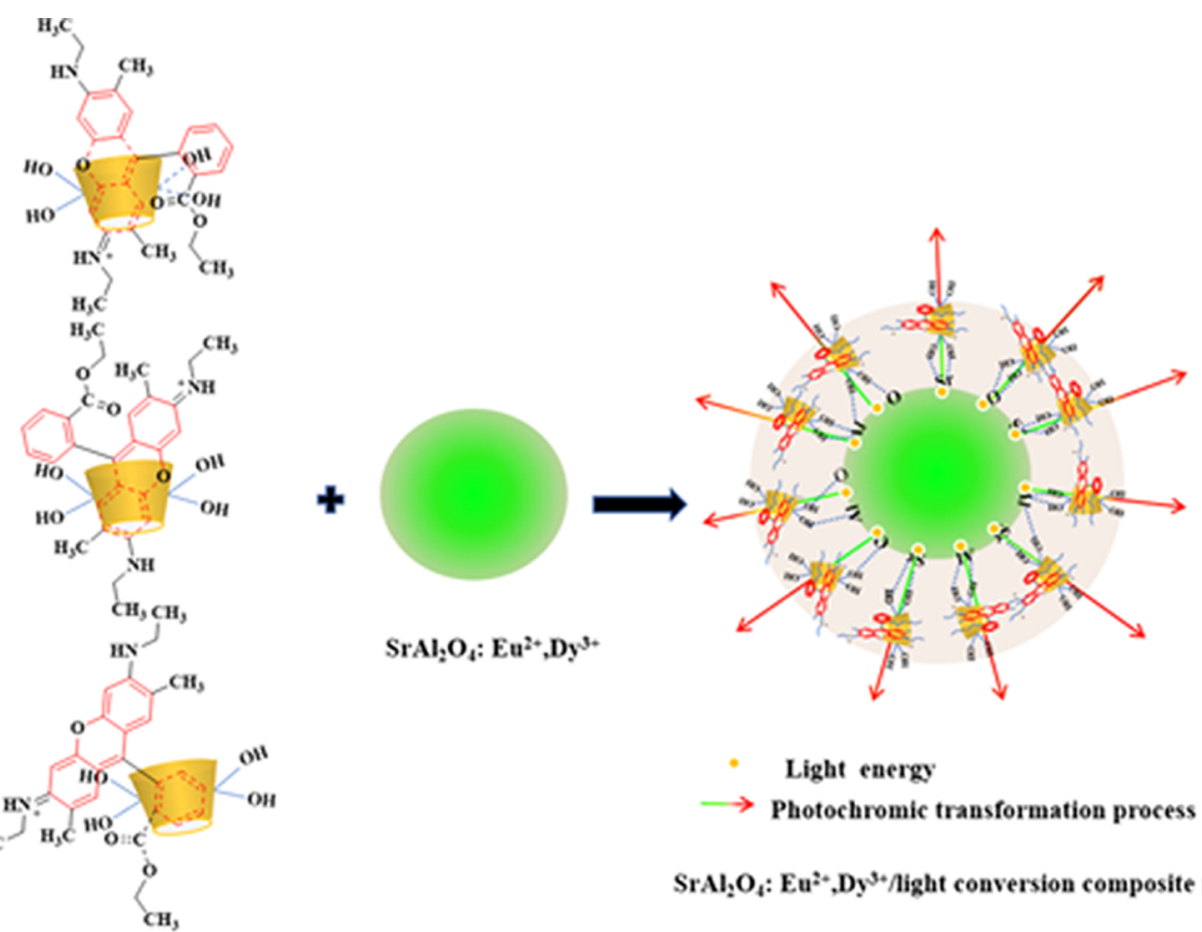

- Light energy

$\longrightarrow$ Photochromic transformation process

$\mathrm{SrAl}_{2} \mathrm{O}_{4}: \mathrm{Eu}^{2}{ }^{*}, \mathrm{Dy}^{3}{ }^{*} /$ ight conversion composite material

The cyclodextrin inclusion compounds

Figure 1. Illustration of the synthesis process of the $\mathrm{SrAl}_{2} \mathrm{O}_{4}: \mathrm{Eu}^{2+}, \mathrm{Dy}^{3+} /$ light conversion composite material.

To enhance the luminous intensity, supramolecular assemblies based on macro-cycles, including ionic crown ethers, ${ }^{19,20}$ ionic macrocyclic arenes, ${ }^{21,22}$ cyclodextrins, ${ }^{23-25}$ cucurbiturils, ${ }^{26,27}$ etc., have been a research hotspot topic in recent years. Because fluorescent molecules are sensitive to their steric environments, the preparation of highly fluorescent photofunctional materials by accommodating fluorophore guests in coordinating hosts and macrocyclic receptors, socalled spatial confinement, has emerged as a highly promising strategy. ${ }^{28-32}$ Cyclodextrins (CDs) are naturally occurring water-soluble toroidally shaped polysaccharides with a hydrophobic central cavity and hydrophilic exterior. ${ }^{33,34}$ The highly hydrophobic central cavity of CDs enables it to form inclusion complexes with a variety of substrates. ${ }^{35}$ (2-Hydroxypropyl) $-\beta$ cyclodextrin (HP- $\beta$-CD) is derived from $\beta$-CD. Compared to $\beta$-CD, HP- $\beta$-CD has much higher water solubility and low toxicity. ${ }^{36,37}$ In this work, the HP- $\beta$-CD as a carrier was employed to form an inclusion compound with rhodamine 6G (Rh6G). Thus, the fluorophores were spatially and electronically confined to avoid photoelectric energy coupling or quenching, thereby achieving enhancement of fluorescence intensity. Then, the SAOED long-lasting phosphor, as the phosphorescent light source, was prepared. The inclusion complex of Rh6G with HP- $\beta$-CD with high fluorescence intensity and a large molar absorption coefficient was used as the light conversion agent. Finally, the cyclodextrin inclusion compounds were coated on the surface of SAOED at a certain mass ratio through a silane coupling agent. Meanwhile, there are a large number of hydroxyl groups on the outside of the cyclodextrin, ${ }^{33}$ which bond to aluminum, strontium, oxygen, and other atoms on the surface of the phosphorescent light source through hydrogen bonding and electrostatic interaction. Consequently, it shortens the distance between the light conversion agent and the surface of the light source and reduces the energy loss in the photon transfer process. ${ }^{38}$ At the same time the surface coating effect of the SAOED is improved. The light conversion layer absorbed continuously emitted photons from SAOED and then emitted light through the down-conversion mechanism, ${ }^{16,39}$ as shown in Figure 1.

\section{RESULTS AND DISCUSSION}

Fourier-transform infrared (FT-IR) spectra of HP- $\beta$-CD, $\mathrm{Rh} 6 \mathrm{G}$, and the cyclodextrin inclusion compounds are displayed in Figure 2. The peaks of the hydroxyl stretching resonances of

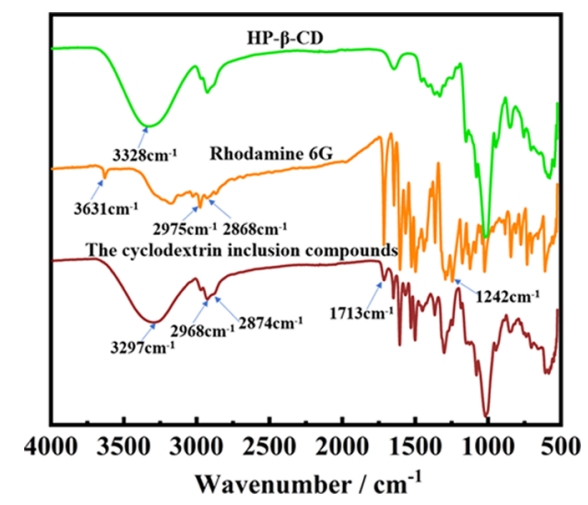

Figure 2. FT-IR spectra of HP- $\beta$-CD, Rh6G, and the inclusion complex of Rh6G with HP- $\beta$-CD.

HP- $\beta$-CD shifted from 3328 to $3297 \mathrm{~cm}^{-1}$ and the intensity of the bands also reduced due to the strong hydrogen bond interaction between hydroxyl groups of HP- $\beta$-CD and the carbonyl and the ester group of Rh6G molecules. The specific peaks at 2975 and $2868 \mathrm{~cm}^{-1}$, which correspond to the methyl stretching resonances of Rh6G, shifted to 2968 and $2874 \mathrm{~cm}^{-1}$ because the methyl groups were present (included) in the nanocavity of HP- $\beta$-CD and the dipolar interaction of the methyl groups proton with the cavity proton. The hydrogen 
bond interaction between the $\mathrm{NH}$ bond of Rh6G and the glycosidic bonds inside the HP- $\beta$-CD cavity may restrict the rotation of the $\mathrm{NH}$ bond, so the $\mathrm{NH}$ stretching resonances at $3631 \mathrm{~cm}^{-1}$ disappeared. The $\mathrm{Ar}-\mathrm{CO}-\mathrm{O}-(\mathrm{C}=\mathrm{O})$ and the ester group (COC) stretching resonance peak intensity was significantly weak, indicating the formation of strong hydrogen bond interaction between HP- $\beta$-CD and Rh6G, after the HP$\beta$-CD formed the inclusion compounds with Rh6G.

The UV-vis absorption spectra of HP- $\beta$-CD, Rh6G, and the cyclodextrin inclusion compounds were recorded, as shown in Figure 3. It can be observed in Figure $3 \mathrm{c}$ that the HP- $\beta$-CD

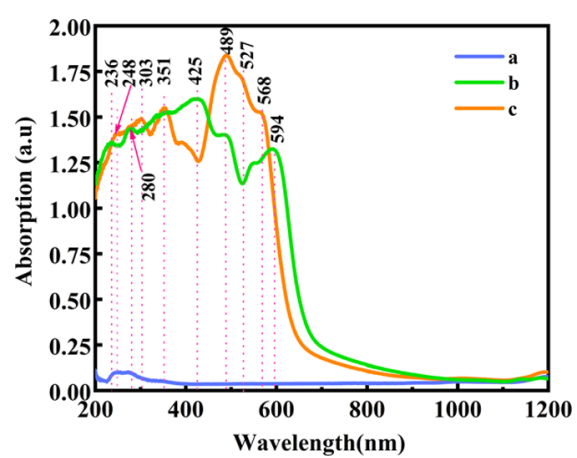

Figure 3. UV-vis absorption spectra of HP- $\beta$-CD (a), Rh6G (b), and the inclusion complex of Rh6G with HP- $\beta$-CD (c).

shows no absorption in the range of 300-1200 $\mathrm{nm}$ and exhibits slight absorption in the range of $220-300 \mathrm{~nm} .{ }^{40}$ Rh6G had seven absorption peaks in the scanned range. When the inclusion complex was formed, there were several changes in the UV-vis absorption spectra of the cyclodextrin inclusion compounds compared with that of Rh6G. The absorption peak of Rh6G at $236 \mathrm{~nm}$ shifted to $248 \mathrm{~nm}$. The absorption peaks of Rh6G at 280 and $351 \mathrm{~nm}$ were slightly affected by the formation of the complex. The absorption peak of Rh6G at 527,489 , and $425 \mathrm{~nm}$ increased greatly. The absorption peak of Rh6G at $594 \mathrm{~nm}$ increased and blue-shifted to $568 \mathrm{~nm}$. These changes are mainly caused by the host-guest interaction of the HP- $\beta$-CD/Rh6G complex, because HP- $\beta$ $\mathrm{CD}$ showed no absorption in the scanned range. Therefore, the absorption peaks were weakened or shifted, confirming the formation of the cyclodextrin inclusion compounds. ${ }^{41,42}$

${ }^{1} \mathrm{H}$ NMR spectra provide one of the most direct evidence for the formation of the inclusion complex. ${ }^{43}{ }^{1} \mathrm{H}$ NMR spectra of HP- $\beta-\mathrm{CD}$, Rh6G, and the inclusion complex of Rh6G with $\mathrm{HP}-\beta$-CD are shown in Figure S1. ${ }^{1} \mathrm{H}$ NMR spectra of the inclusion complex showed the proton peaks of both HP- $\beta$-CD and Rh6G. Since the interactions between the host and guest molecules are through noncovalent bonding such as van der Waals forces and hydrogen bonds instead of chemical bonds, the chemical shifts $(\Delta \delta)$ in the complex were small. ${ }^{44}$ Several ${ }^{1} \mathrm{H}$ chemical shifts of Rh6G were changed and $\Delta \delta$ of the protons $\mathrm{H}-3$ was 0.08 ppm (Figure S1). Furthermore, Table 1 lists the chemical shifts $(\delta)$ of HP- $\beta$-CD before and after forming a complex with Rh6G and the variation of ${ }^{1} \mathrm{H}$ chemical shifts $(\Delta \delta)$. The ${ }^{1} \mathrm{H}$ chemical shifts of HP- $\beta$-CD were consistent with the former report. ${ }^{40}$ Almost all of the ${ }^{1} \mathrm{H}$ chemical shifts of HP- $\beta$-CD were changed. The variation of ${ }^{1} \mathrm{H}$ chemical shift confirmed that the inclusion complex was formed.

Thermogravimetric analysis (TGA) and differential scanning calorimetry (DSC) curves of HP- $\beta$-CD, Rh6G, and the inclusion complex of $\mathrm{Rh} 6 \mathrm{G}$ with $\mathrm{HP}-\beta-\mathrm{CD}$ are illustrated in Figure $4 a-c$, respectively. The HP- $\beta$-CD exhibited a steep onestep mass loss between 303 and $403{ }^{\circ} \mathrm{C}$ (Figure 4a). The decomposition started at $303{ }^{\circ} \mathrm{C}$ and ended at $403{ }^{\circ} \mathrm{C}$, which is consistent with the former paper. ${ }^{41}$ Meanwhile, DSC shows the fusion and degradation of HP- $\beta$-CD at 354 occurs in one step. The thermal decomposition process for Rh6G can be divided into two stages, as shown in Figure $4 \mathrm{~b}$. The first stage begins at $233{ }^{\circ} \mathrm{C}$ and terminates at $265{ }^{\circ} \mathrm{C}$ with a mass loss $10.6 \%$. Meanwhile, the second step starts from 320 to $510^{\circ} \mathrm{C}$ with a mass loss $52.6 \%$. DSC shows four endothermic peaks at $240,305,465$, and $506^{\circ} \mathrm{C}$. DSC shows the melting of Rh6G at 241,465 , and $506{ }^{\circ} \mathrm{C}$ with simultaneous decomposition. In Figure $4 \mathrm{c}$, the TG curve of the inclusion complex of Rh6G with $\mathrm{HP}-\beta$-CD was also one step. The inclusion complex began to decompose at about $245^{\circ} \mathrm{C}$ and this ended at about $603{ }^{\circ} \mathrm{C}$, which is different from HP- $\beta$-CD. DSC analysis shows two endothermic peaks at 276 and $294{ }^{\circ} \mathrm{C}$. The decomposition peak of Rh6G was at $276^{\circ} \mathrm{C}$ and the decomposition peak of HP- $\beta$-CD was at $294{ }^{\circ} \mathrm{C}$. Due to the Van der Waals forces and hydrogen bonds between HP- $\beta$-CD and Rh6G molecules, the initial decomposition temperature of $\mathrm{Rh} 6 \mathrm{G}$ increased by about $35^{\circ} \mathrm{C}$, and the initial decomposition temperature of HP- $\beta$-CD decreased by $60{ }^{\circ} \mathrm{C}$, partly proving the formation of the inclusion complex.

The morphologies of $\mathrm{HP}-\beta-\mathrm{CD}, \mathrm{Rh} 6 \mathrm{G}$, and the inclusion complex of Rh6G with HP- $\beta$-CD powder are shown in Figure $5 \mathrm{a}-\mathrm{c}$, respectively. The scanning electron microscopy (SEM) micrographs of the inclusion complex of Rh6G with HP- $\beta$-CD showed a smooth morphology (Figure $5 \mathrm{c}$ ), while the HP- $\beta$-CD (Figure 3a) and Rh6G (Figure 5b) had a rough surface. The SEM micrographs of the SAOED phosphor particles present irregular shapes with an average diameter of $15 \mu \mathrm{m}$, and show sharp edges and clean surfaces (Figure $5 \mathrm{~d}$ ) compared with the surface of SAOED/light conversion composite material (Figure 5e). The surface of SAOED/light conversion composite material presents a completely different and relatively coarse morphology (Figure 5e), which indicates that the cyclodextrin inclusion compound particles adhered to SAOED. The surface details of the SAOED particles showed much small debris formed after grinding, while the surface details of the SAOED/light conversion composite material present small agglomerates mainly composed of the cyclodextrin inclusion compounds (Figure $5 \mathrm{f}$ ).

Figure S2 shows the energy-dispersive spectrometry (EDS) analysis and X-ray dot mapping of the SAOED/light conversion composite material. The results of EDS analysis

Table 1. Variation of ${ }^{1} \mathrm{H}$ Chemical Shift $(\delta / \mathrm{ppm})$ of HP- $\beta$-CD before and after Forming Complex with Rh6G (DMSO, $\left.300 \mathrm{~K}\right)$

\begin{tabular}{lccccrrrrrr} 
HP- $\beta$-CD & $\mathrm{H}-1$ & $\mathrm{H}-2$ & $\mathrm{H}-3$ & $\mathrm{H}-4$ & $\mathrm{H}-5$ & $\mathrm{H}-6$ & $\mathrm{OCH}_{2}$ & \multicolumn{1}{c}{$\mathrm{CH}_{3}$} & \multicolumn{1}{c}{$\mathrm{OH}$} \\
$\delta_{\text {free }}$ & 4.833 & 3.441 & 3.751 & 3.412 & 3.478 & 3.615 & 3.327 & 1.025 & 5.880 \\
$\delta_{\text {complex }}$ & 4.834 & 3.438 & 3.748 & 3.394 & 3.467 & 3.614 & 3.314 & 1.024 & 5.885 \\
$\Delta \delta$ & 0.001 & -0.003 & 0.003 & -0.018 & -0.011 & -0.001 & -0.013 & -0.001 & 0.005
\end{tabular}



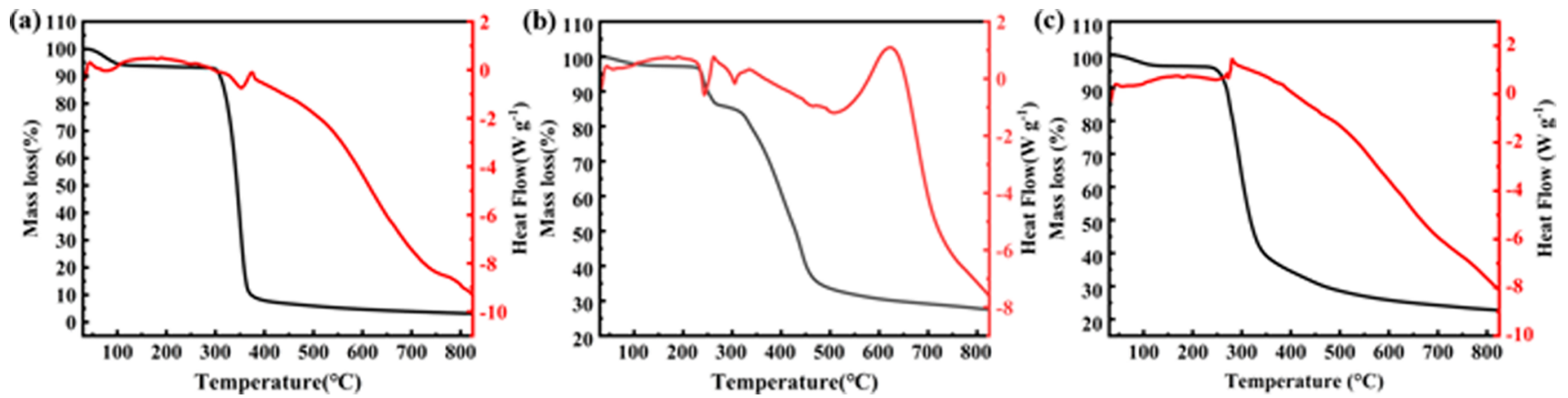

Figure 4. TGA and DSC curves of HP- $\beta$-CD (a), Rh6G (b), and the inclusion complex of Rh6G with HP- $\beta$-CD (c).
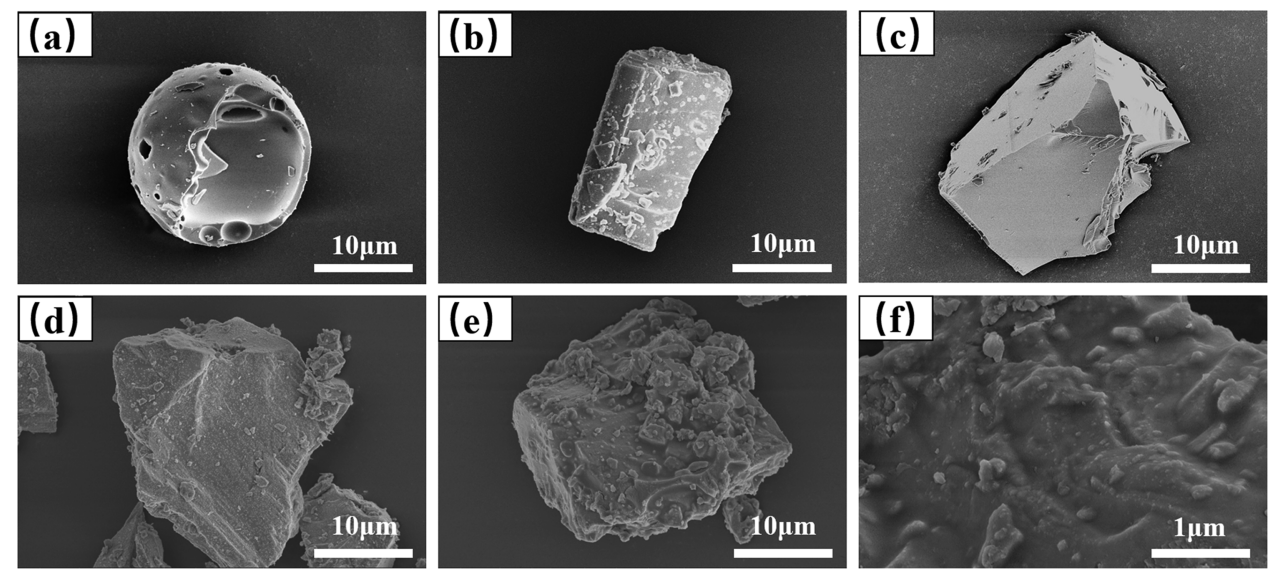

Figure 5. (a) SEM micrograph of HP- $\beta$-CD. (b) SEM micrograph of Rh6G. (c) SEM micrograph of the inclusion complex of Rh6G with HP- $\beta$ CD. (d) SEM micrograph of SAOED. (e) SEM micrograph of the SAOED/light conversion composite material. (f) SEM micrograph of the surface of the SAOED/light conversion composite material.
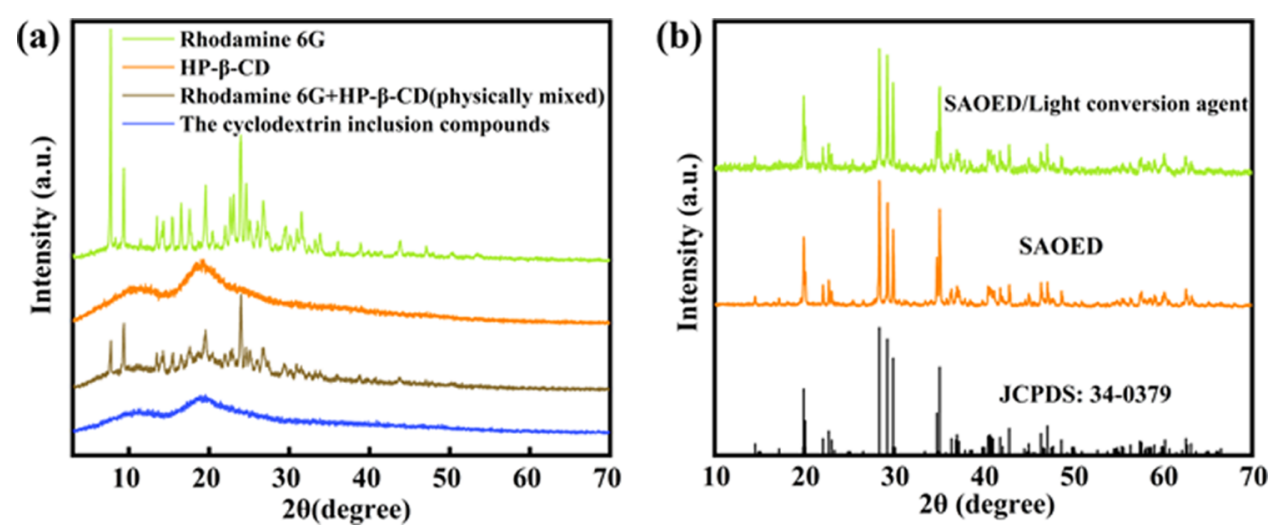

Figure 6. (a) XRD patterns of Rh6G, HP- $\beta$-CD, the physical mixture of Rh6G with HP- $\beta$-CD, and the inclusion of Rh6G with HP- $\beta$-CD. (b) XRD patterns of the SAOED and SAOED/light conversion composite material.

confirm the presence of strontium ( $\mathrm{Sr}$ ), aluminum (Al), oxygen $(\mathrm{O})$, carbon $(\mathrm{C})$, europium $(\mathrm{Eu})$, dysprosium (Dy), chlorine $(\mathrm{Cl})$, and nitrogen $(\mathrm{N})$ elements in the samples. X-ray dot mapping analysis indicates that $\mathrm{C}, \mathrm{Cl}$, and $\mathrm{N}$ elements are uniformly distributed in the surface of the $\mathrm{SrAl}_{2} \mathrm{O}_{4}: \mathrm{Eu}^{2+}, \mathrm{Dy}^{3+}$ host, which indicates that the cyclodextrin inclusion compound particles homogeneously adhered to $\mathrm{SrAl}_{2} \mathrm{O}_{4}: \mathrm{Eu}^{2+}, \mathrm{Dy}^{3+}$.

Crystallinity characterization gives out more information about the formation of the inclusion complex. Figure 5a shows the X-ray diffraction (XRD) patterns of guest (Rh6G), host (HP- $\beta$-CD), physical mixture, and the inclusion of Rh6G with $\mathrm{HP}-\beta$-CD. Actually, pure Rh6G is a crystalline material having several sharp high-intensity peaks at different diffraction angles $(2 \theta)$ of $7.7,9.4,19.6,23.1,23.9,24.6,26.7,31.5,33.9,36.1$, and 38.9. The XRD data of the HP- $\beta$-CD displayed a broad peak, which confirmed its amorphous structures, consistent with the result in ref 45 . The physical mixture (Figure 5a) reflects an overlapping pattern of both $\mathrm{Rh} 6 \mathrm{G}$ and $\mathrm{HP}-\beta$-CD. In the case of the inclusion complex, the pattern is significantly different from those of individual components and the physical mixture. The regular pattern of the solid inclusion complex disappears, which strongly suggests that Rh6G molecules were encapsulated in the HP- $\beta$-CD cavity and ulteriorly proves that 

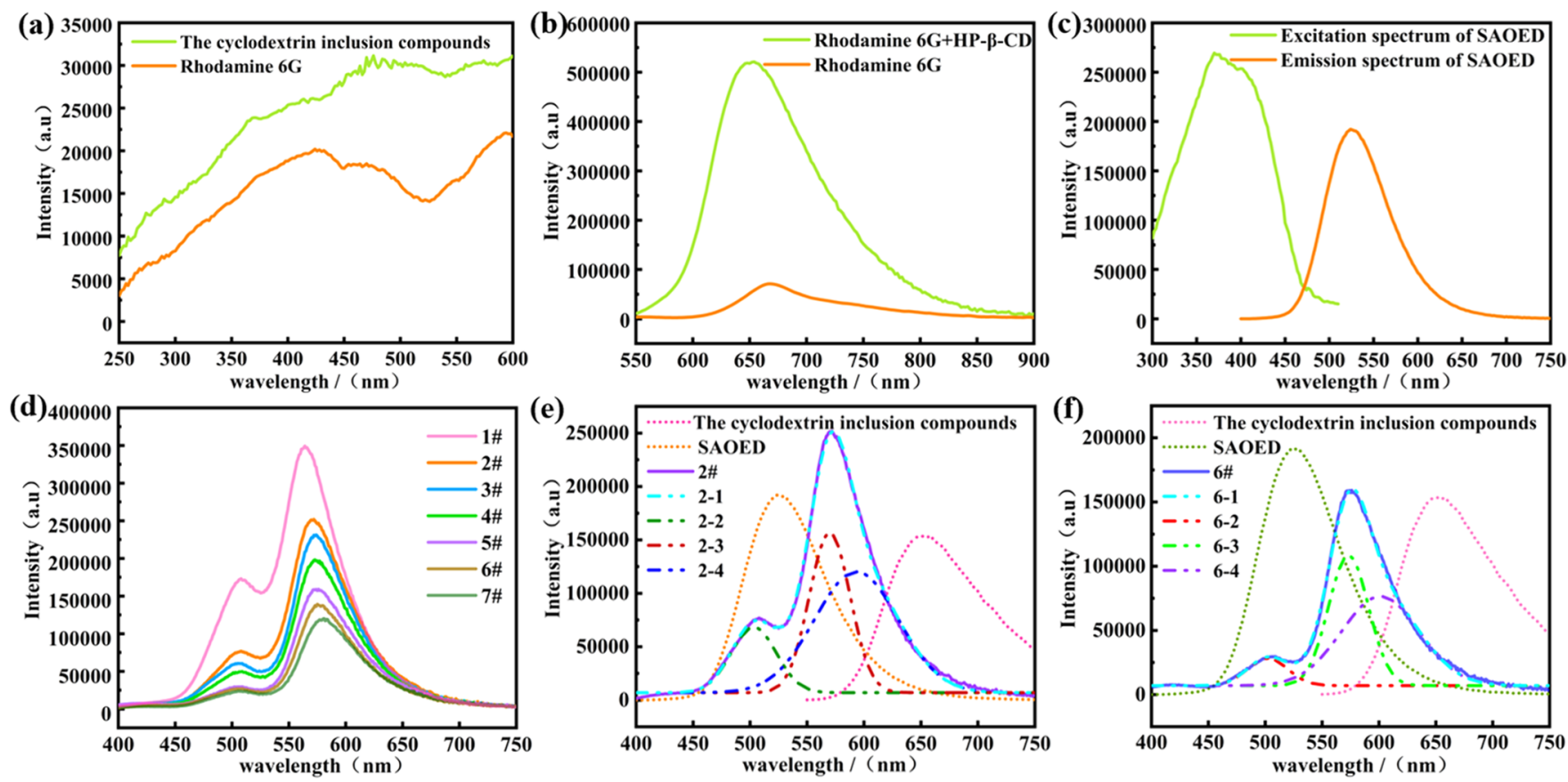

Figure 7. (a) Excitation spectra of the cyclodextrin inclusion compounds and Rh6G $\left(\left(\lambda_{\mathrm{EM}}=653 \mathrm{~nm}\right)\right)$. (b) Emission spectra of the cyclodextrin inclusion compounds and Rh6G $\left(\lambda_{\mathrm{EX}}=525 \mathrm{~nm}\right)$. (c) Excitation $\left(\lambda_{\mathrm{EM}}=525 \mathrm{~nm}\right)$ and emission $\left(\lambda_{\mathrm{EX}}=365 \mathrm{~nm}\right)$ spectra of the SAOED phosphor. (d) Emission spectrum $\left(\lambda_{\mathrm{EX}}=365 \mathrm{~nm}\right)$ of the SAOED/light conversion composite material with various contents of the cyclodextrin inclusion compounds ( $1 \#=3 \mathrm{wt} \%, 2 \#=5 \mathrm{wt} \%, 3 \#=7 \mathrm{wt} \%, 4 \#=8 \mathrm{wt} \%, 5 \#=9 \mathrm{wt} \%, 6 \#=10 \mathrm{wt} \%, 7 \#=11 \mathrm{wt} \%)$. Multi-peak fitting curve of the prepared $2 \#(e)$ and $6 \#(f)$ samples.

intermolecular interaction exists between $\mathrm{HP}-\beta-\mathrm{CD}$ and $\mathrm{Rh} 6 \mathrm{G},{ }^{46,47}$ which is consistent with IR spectra.

The XRD patterns of the SAOED and SAOED/light conversion composite material are shown in Figure $6 \mathrm{~b}$. Through analysis of data using MDI Jade5.0 software, the characteristic diffraction peaks of the prepared SAOED were identical to those of the monoclinic $\mathrm{SrAl}_{2} \mathrm{O}_{4}$ phase (JPCDS No. 34-0379), which means that we successfully prepared the SAOED phosphors. The characteristic XRD peaks of the cyclodextrin inclusion compounds in the XRD patterns of coated samples are not found because the coating light conversion agent is amorphous (Figure 6b). This indicates that the coating of the cyclodextrin inclusion compounds does not affect the phase of SAOED, which ensured that light source luminescence properties and light conversion process is achieved by the cyclodextrin inclusion compounds.

As shown in Figure 7a, after the formation of the Rh6G/HP$\beta$-CD inclusion complex, the excitation spectrum of the light converter was significantly enhanced, indicating that the inclusion complex was more efficiently excited. Meanwhile, the emission spectrum of the cyclodextrin inclusion compound (Figure 7b) displayed a broad visible band. More importantly, the maximum fluorescence emission intensity of the Rh6G/ $\mathrm{HP}-\beta$-CD inclusion complex is about 10 times stronger than that of Rh6G, which briefly illustrates the formation of the inclusion complex. The fluorophore is mainly deactivated through nonradiative routes at room temperature due to the active intramolecular vibrations and rotations. ${ }^{48,49}$ As the size of the cavity of the cyclodextrin molecule ${ }^{50}$ can only accommodate one Rh6G molecule, the nanoconfined space in the cavity of $\mathrm{HP}-\beta-\mathrm{CD}$ can effectively prevent the nonradiative relaxation by locking the Rh6G fluorophore and inhibiting their intramolecular motions, resulting in enhanced fluorescence. In addition, the inclusion of Rh6G with HP- $\beta$ -
CD produces both spatial and electronic isolation of the fluorophores. So, it avoids the photoelectric energy coupling and the quenching of the emitted fluorescence to realize the enhancement of the fluorescence intensity of the light conversion agent. An increase in the fluorescence intensity on the formation of an inclusion complex was observed earlier. $^{51-53}$

The spectrum of SAOED/light conversion composite material with various contents of the cyclodextrin inclusion compounds (Figure 7d) exhibits two broad emission bands, compared with that of SAOED (Figure 7c). The peak between 450 to $530 \mathrm{~nm}$ (peak I) is assigned to the phosphorescence emission of SAOED and the peak between 530 and $650 \mathrm{~nm}$ (peak II) is assigned to the fluorescence emission of the cyclodextrin inclusion compounds. The emission peak at 525 $\mathrm{nm}$ is assigned to $4 \mathrm{f}^{6} 5 \mathrm{~d}^{1}$ to $4 \mathrm{f}^{7}$ transition of $\mathrm{Eu}^{2+}$ ions. ${ }^{39,54}$ The role of $\mathrm{Dy}^{3+}$ is to form a hole trap level and prolong the afterglow. ${ }^{5,56}$ With the cyclodextrin inclusion compounds content increasing, the emission peak at around $580 \mathrm{~nm}$ shifts to the right gradually, which is because the red light component increases and electronic interaction exists among the cyclodextrin inclusion compounds. It can also be seen from the figure that the intensity of the red light band is much higher than that of the green light band, so the composite phosphor successfully realizes the conversion and energy transfer from green to yellow or orange light. The emission peak of $2 \#$ (Figure $7 \mathrm{e}$ ) and $6 \#$ samples (Figure $7 \mathrm{f}$ ) were well fitted, in which fitting curves $2-1$ and $6-1$ could be divided into $2-2,2-3,2-4$ and $6-2,6-3,6-4$ three-component peaks, respectively. The ratio of peak area is 0.15:0.33:0.52 for fitting peak 2-2, 2-3, 2-4 and 0.08:0.39:0.53 for fitting peak $6-2,6-3,6-4$, respectively, which is consistent with the concentration ratio of adding the cyclodextrin inclusion compounds. Although the physical meaning of the three- 

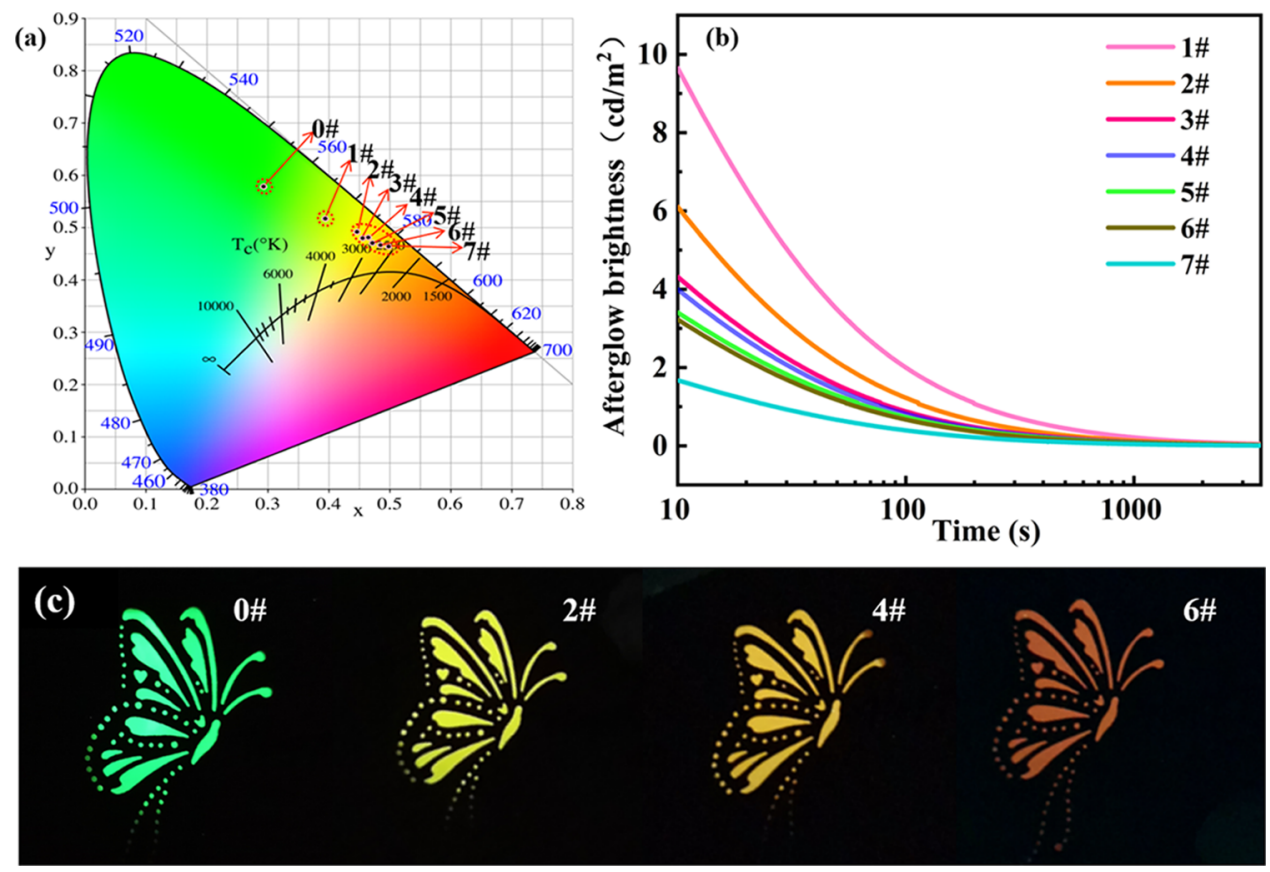

Figure 8. (a) CIE 1931 chromaticity diagram for SAOED and SAOED/light conversion composite materials with various contents of the cyclodextrin inclusion compounds ( $1 \#=3 \mathrm{wt} \%$, $2 \#=5 \mathrm{wt} \%$, $3 \#=7 \mathrm{wt} \%, 4 \#=8 \mathrm{wt} \%, 5 \#=9 \mathrm{wt} \%, 6 \#=10 \mathrm{wt} \%$, 7\# = 11 wt \%). (b) Afterglow decay curves $(0-3600 \mathrm{~s})$ of the SAOED/light conversion composite material with various cyclodextrin inclusion compounds $(1 \#=3 \mathrm{wt} \%, 2 \#=5$ $\mathrm{wt} \%, 3 \#=7 \mathrm{wt} \%, 4 \#=8 \mathrm{wt} \%, 5 \#=9 \mathrm{wt} \%, 6 \#=10 \mathrm{wt} \%, 7 \#=11 \mathrm{wt} \%$ ). (c) Optical images photographed in a darkroom by casting the SAOED/light conversion composite material with various content of the cyclodextrin inclusion compounds onto the flexible silicone logo substrates (afterglow images recorded at a delay time of 5 min after saturated excitation with a $365 \mathrm{~nm} \mathrm{UV} \mathrm{lamp).}$

component peak was not clear, it is significant that this method can be used to make a semi-quantitative interpretation.

Under $365 \mathrm{~nm}$ excitation, the steady-state photoluminescent quantum yield $\left(\eta_{\mathrm{PLQY}}\right)$ of the SAOED/light conversion composite material (1\#-7\#) are summarized in Table S1, and the measurement details are shown in Figure S3. Because the SAOED/light conversion composite material in this work is a long afterglow material, the absorbed energy is continuously and slowly released instead of being completely released in a short time. Therefore, the photoluminescence quantum yield is about $10 \%$. However, the absorption efficiency $\left(\alpha_{\mathrm{abs}}\right)$ of the SAOED/light conversion composite material $(1 \#-7 \#)$ is about $55 \%$.

Figure 8 a shows the CIE chromaticity diagram of SAOED/ light conversion composite material with different mass ratios. The emitting color of SAOED/light conversion composite material was a mixed fluorescence color consisting of SAOED and the cyclodextrin inclusion compound, which can be controlled by varying the concentration of the cyclodextrin inclusion compounds. Apparently, the color coordinates of the uncoated SAOED were located in the green area with the coordinate of $(x=0.2933, y=0.5789)$. The color coordinates position of the novel material presented an obvious redshift from the green region to the yellow and orange regions as the cyclodextrin inclusion compound coating increased. The color coordinate position of the SAOED/light conversion composite material reached the yellow area with a coordinate of $(x=$ $0.4472, y=0.4924)$ when the cyclodextrin inclusion compounds content was added to $5 \%$, and then arrived the orange area with the coordinate of $(x=0.4856, y=0.4667)$ when the cyclodextrin inclusion compounds were added at $10 \%$. Thus, by coating the cyclodextrin inclusion compounds, we have successfully realized persistent luminescence tuning.
Figure $8 \mathrm{~b}$ shows the afterglow decay curves of the SAOED/ light conversion composite material, the corresponding data of which are summarized in Table S2. The afterglow decay process can be divided into two processes: rapid decay and slow decay processes. ${ }^{57,58}$ The initial stage is the fastest process of the afterglow brightness decay and then the decay rate gradually slows down. These afterglow decay plots show a similar tendency, which verifies the similar radiative energy transfer mechanism. ${ }^{16}$ As the cyclodextrin inclusion compounds coating increased, the afterglow initial brightness gradually decreases. This is because the SAOED/light conversion composite material has a core-shell structure. The shell part absorbed and reflected a fraction of light, causing the absorbed energy of the core SAOED to reduce. Consequently, the photons emitted by SAOED were significantly reduced. ${ }^{1618}$ The higher the content of light conversion agent coating, the less light energy can be absorbed by the SAOED core. ${ }^{59}$ Therefore, the initial afterglow brightness of the SAOED/light conversion composite material decreased gradually with the increase of the content of the light conversion layer. As shown in Figure 8c, by means of casting the SAOED/light conversion composite material samples onto the flexible silicone substrates, we fabricated colorful design patterns.

\section{CONCLUSIONS}

In summary, we developed a facile route for preparing efficient light conversion materials using (2-hydroxypropyl)- $\beta$-cyclodextrin (HP- $\beta$-CD) to form inclusion compounds with Rhodamine 6G (Rh6G). It was demonstrated that the maximum fluorescence emission intensity of Rh6G/HP- $\beta$-CD inclusion compounds is about 10 times stronger than that of Rh6G. Moreover, we have realized persistent luminescence 
tuning using the as-prepared cyclodextrin inclusion compounds as light conversion materials. Our strategy provides a useful method for fine-tuning the persistent luminescence of afterglow phosphors and can be extended to other energy storage and light conversion materials. This strategy may open up new opportunities for persistent luminescence materials toward many emerging applications.

\section{EXPERIMENTAL SECTION}

4.1. Materials and Synthesis. Aluminum oxide $\left(\mathrm{Al}_{2} \mathrm{O}_{3}\right.$, 99.99\%), strontium carbonate $\left(\mathrm{SrCO}_{3}, 99.99 \%\right)$, europium nitrate hexahydrate $\left(\mathrm{Eu}\left(\mathrm{NO}_{3}\right)_{3}, 99.99 \%\right)$, dysprosium nitrate hexahydrate $\left(\mathrm{Dy}\left(\mathrm{NO}_{3}\right)_{3}, 99.99 \%\right)$, boric acid $\left(\mathrm{H}_{3} \mathrm{BO}_{3}, \mathrm{AR}\right)$, (2-hydroxypropyl)- $\beta$-cyclodextrin (HP- $\beta$-CD, 97\%), (3aminopropyl)triethoxysilane (KH-550, 98\%) and ethanol $\left(\mathrm{C}_{2} \mathrm{H}_{5} \mathrm{OH}, \mathrm{AR}\right)$ were purchased from Aladdin Chemistry Co., Ltd. (Shanghai, China). Rhodamine 6G (Rh6G, AR) was purchased from Macklin Chemistry Co., Ltd. (Shanghai, China). All of the reagents were used as received without any further purification.

4.2. Preparation of the Light Conversion Agent. Cyclodextrin inclusion compounds were prepared by the saturated aqueous solution method according to ref 60 . Accurately weighed $2 \mathrm{~g}$ of $\mathrm{HP}-\beta$-CD was added to $500 \mathrm{~mL}$ of deionized water, followed by ultrasound for 30 minutes, and then allowed to stand overnight. The HP- $\beta$-CD solution was added to rhodamine $6 \mathrm{G}$ solution $\left(n_{\mathrm{HP}-\beta-\mathrm{CD}} / n_{\mathrm{Rh}-6 \mathrm{G}}=1: 1\right)$. The mixed solution was continuously stirred for $5 \mathrm{~h}$ at $40{ }^{\circ} \mathrm{C}$. Then, the reaction mixture was dried at $105^{\circ} \mathrm{C}$ for $10 \mathrm{~h}$ and the solid was ground to powder. Finally, the light conversion agent (cyclodextrin inclusion compounds) was obtained.

4.3. Preparation of SAOED Phosphors. The powders of SAOED phosphors were synthesized by the solid-state reactions according to ref 61. The molar ratio of $\mathrm{SrCO}_{3}$, $\mathrm{Al}_{2} \mathrm{O}_{3}, \mathrm{Eu}\left(\mathrm{NO}_{3}\right)_{3}, \mathrm{Dy}\left(\mathrm{NO}_{3}\right)_{3}$, and $\mathrm{H}_{3} \mathrm{BO}_{3}$ is 1:1:0.02:0.04:0.1. The starting materials were mixed thoroughly in a ball mill for $4 \mathrm{~h}$ and subsequently heated to $1350^{\circ} \mathrm{C}$ under a mild reducing atmosphere of activated carbon for $4 \mathrm{~h}$. After cooling, the sintered products were re-milled and sieved to get the phosphors.

4.4. Preparation of SAOED/Light Conversion Agent Complexes. Accurately weighed cyclodextrin inclusion compounds and as-prepared SAOED with different weight ratios ( $0 \#=0 \mathrm{wt} \%, 1 \#=3 \mathrm{wt} \%, 2 \#=5 \mathrm{wt} \%, 3 \#=7 \mathrm{wt} \%, 4 \#$ $=8 \mathrm{wt} \%, 5 \#=9 \mathrm{wt} \%, 6 \#=10 \mathrm{wt} \%, 7 \#=11 \mathrm{wt} \%)$ were put into a flask, and then added with ethanol. The mixture was continuously stirred for $10 \mathrm{~min}$ at $40{ }^{\circ} \mathrm{C}$ and then (3aminopropyl)triethoxysilane was added. The ratio of (3aminopropyl)triethoxysilane added was $10 \mathrm{wt} \%$ of the cyclodextrin inclusion compounds. The mixture was continuously stirred for $30 \mathrm{~min}$ at $70{ }^{\circ} \mathrm{C}$, and it was evaporated in a vacuum. After removing the solvent, the samples were dried at $100{ }^{\circ} \mathrm{C}$ for $2 \mathrm{~h}$, and the products were milled and sieved to get the desired samples.

4.5. Characterization and Measurements. The samples were tested using a Fourier-transform infrared (FT-IR) spectrometer (Thermo Fisher Nicolet iS 50) in the range of $400-4000 \mathrm{~cm}^{-1}$ with a resolution of $4 \mathrm{~cm}^{-1}$. The ${ }^{1} \mathrm{H}$ NMR spectra were recorded on the Bruker AVANCE III $500 \mathrm{MHz}$ spectrometer. Ultraviolet-visible (UV-vis) absorption spectra were recorded on a Cary 5000 spectrophotometer. Thermogravimetric (TGA) measurements and differential scanning calorimetry (DSC) were carried out on a Mettler Toledo
DSC1 at a heat ramp of $10{ }^{\circ} \mathrm{C} \mathrm{min}^{-1}$ under nitrogen. The surface morphologies of the SAOED phosphor particles and SAOED/light conversion composite material phosphor were inspected using a field emission scanning electron microscope (FESEM, Thermo Fisher-Apreo S LoVac). EDS analysis and $\mathrm{X}$-ray dot mapping of the SAOED/light conversion composite material were performed using a Bruker energy-dispersive Xray spectrometer (QUANTAX 200 with XFlash 6/100). X-ray diffraction (XRD) measurements were carried out on the Rigaku Miniflex $600(\mathrm{Cu} \mathrm{K} \alpha$ radiation, $\lambda=1.5418 \AA)$ with an angle range of $2 \theta=3-70^{\circ}$. The photoluminescence performance (excitation and emission spectrum) spectra, steady-state photoluminescent quantum yield and CIE chromaticity coordinates were measured using the Edinburgh Instruments FLS 980 Fluorescence spectrometer (under $365 \mathrm{~nm}$ excitation). Afterglow decay curves were tested using a PR305 afterglow brightness tester (SENSING Instruments Co., Ltd., China) where the samples were excited by a $150 \mathrm{~W}$ xenon arc lamp, and the excitation wavelength was $365 \mathrm{~nm}$. The excitation time is $15 \mathrm{~min}$ with excitation illumination of $1000 \mathrm{~lx}$ to ensure that our samples fully absorb energy. The detector used was Hamamatsu CR114. The data were recorded $10 \mathrm{~s}$ later. All of the measurements were carried out at room temperature.

\section{ASSOCIATED CONTENT}

\section{Supporting Information}

The Supporting Information is available free of charge at https://pubs.acs.org/doi/10.1021/acsomega.1c03670.

${ }^{1} \mathrm{H}$ NMR spectra of the inclusion complex of Rh6G with HP- $\beta$-CD (a), Rh6G (b), and HP- $\beta$-CD (c) (Figure $\mathrm{S} 1)$; EDS spectrum of the SAOED/light conversion composite material and elemental distribution state of the SAOED/light conversion composite material (Figure S2); excitation lines of $\mathrm{BaSO}_{4}$ and $1 \#$, and the emission spectrum of $1 \#$ collected using an integrating sphere. The inset shows a magnification of the emission spectrum of 1\# (Figure S3); the photoluminescent quantum yield ( $\left.\eta_{\mathrm{PLQY}}\right)$ and absorption efficiency $\left(\alpha_{\mathrm{abs}}\right)$ of the SAOED/light conversion composite material (1\#-7\#) (Table S1); and summary of the afterglow decay curves of SAOED/light conversion composite material (1\#-7\#, afterglow brightness, $\left.\mathrm{mcd} / \mathrm{m}^{2}\right)($ Table S2) (PDF)

\section{AUTHOR INFORMATION}

\section{Corresponding Authors}

Lijun Song - CAS Key Laboratory of Design and Assembly of Functional Nanostructures, and Fujian Key Laboratory of Nanomaterials, Fujian Institute of Research on the Structure of Matter, Chinese Academy of Sciences, Fuzhou, Fujian 350002, China; Fujian Science \& Technology Innovation Laboratory for Optoelectronic Information of China, Fuzhou 350002, China; Xiamen Institute of Rare Earth Materials, Haixi Institute, Chinese Academy of Sciences, Xiamen 361021, China; Xiamen Key Laboratory of Rare Earth Photoelectric Functional Materials, Chinese Academy of Sciences, Xiamen 361021, China; ㅇo이.org/0000-00022820-6866; Email: slj@fjirsm.ac.cn

Linxi Hou - College of Chemical Engineering, Fuzhou University, Fuzhou, Fujian 350108, China; 이이.org/ 0000-0002-7962-0936; Email: 1xhou@fzu.edu.cn 


\section{Author}

Dan Zhao - College of Chemical Engineering, Fuzhou University, Fuzhou, Fujian 350108, China; CAS Key Laboratory of Design and Assembly of Functional Nanostructures, and Fujian Key Laboratory of Nanomaterials, Fujian Institute of Research on the Structure of Matter, Chinese Academy of Sciences, Fuzhou, Fujian 350002, China; Fujian Science \& Technology Innovation Laboratory for Optoelectronic Information of China, Fuzhou 350002, China; Xiamen Institute of Rare Earth Materials, Haixi Institute, Chinese Academy of Sciences, Xiamen 361021, China; Xiamen Key Laboratory of Rare Earth Photoelectric Functional Materials, Chinese Academy of Sciences, Xiamen 361021, China

Complete contact information is available at: https://pubs.acs.org/10.1021/acsomega.1c03670

\section{Notes}

The authors declare no competing financial interest.

\section{ACKNOWLEDGMENTS}

This work is supported by the Fujian Science \& Technology Innovation Laboratory for Optoelectronic Information of China (2021ZR122), the project "The Key Technology of Rare Earth Long Glow Materials" and the Joint Luminescent Fibre Lab by Xinsiyuan New Materials Co. Ltd. and Xiamen Institute of Rare Earth Materials.

\section{REFERENCES}

(1) Siraj, N.; El-Zahab, B.; Hamdan, S.; Karam, T. E.; Haber, L. H.; Li, M.; Fakayode, S. O.; Das, S.; Valle, B.; Strongin, R. M.; et al. Fluorescence, Phosphorescence, and Chemiluminescence. Anal. Chem. 2016, 88, 170-202.

(2) Matsuzawa, T.; Aoki, Y.; Takeuchi, N.; Murayama, Y. A New Long Phosphorescent Phosphor with High Brightness, $\mathrm{SrAl}_{2} \mathrm{O}_{4}: \mathrm{Eu}^{2+}$, $\mathrm{Dy}^{3+}$. J. Electrochem. Soc. 1996, 143, 2670-2673.

(3) Jung, K. Y.; Lee, H. W.; Jung, H. Luminescent Properties of ( $\mathrm{Sr}$, $\mathrm{Zn}) \mathrm{Al} 2 \mathrm{O} 4: \mathrm{Eu}^{2+}, \mathrm{B}^{3+}$ Particles as a Potential Green Phosphor for UV LEDs. Chem. Mater. 2006, 18, 2249-2255.

(4) Liu, X.; Chen, X.; Yu, Y.; Xie, W.; Zhao, Y.; Luo, S.; Mei, G.; Lin, J. Broad-Band Excited and Tunable Luminescence of $\mathrm{CaTbAl}_{3} \mathrm{O}_{7}$ : $\mathrm{RE}^{3+}\left(\mathrm{RE}^{3+}=\mathrm{Ce}^{3+}\right.$ and $/$ or Eu $\left.{ }^{3+}\right)$ Nanocrystalline Phosphors for NearUV WLEDs. Inorg. Chem. 2020, 59, 12348-12361.

(5) Lin, H.; Wang, B.; Xu, J.; Zhang, R.; Chen, H.; Yu, Y.; Wang, Y. Phosphor-in-Glass for High-Powered Remote-Type White AC-LED. ACS Appl. Mater. Interfaces 2014, 6, 21264-21269.

(6) Dirin, D. N.; Protesescu, L.; Trummer, D.; Kochetygov, I. V.; Yakunin, S.; Krumeich, F.; Stadie, N. P.; Kovalenko, M. V. Harnessing Defect-Tolerance at the Nanoscale: Highly Luminescent Lead Halide Perovskite Nanocrystals in Mesoporous Silica Matrixes. Nano Lett. 2016, 16, 5866-5874.

(7) Wang, P.; Xu, X.; Zhou, D.; Yu, X.; Qiu, J. Sunlight Activated Long-Lasting Luminescence from $\mathrm{Ba}_{5} \mathrm{Si}_{8} \mathrm{O}_{21}: \mathrm{Eu}^{2+}, \mathrm{Dy}^{3+}$ Phosphor. Inorg. Chem. 2015, 54, 1690-1697.

(8) Finley, E.; Cobb, A.; Duke, A.; Paterson, A.; Brgoch, J. Optimizing Blue Persistent Luminescence in $\left(\mathrm{Sr}_{1-\delta} \mathrm{Ba}_{\delta}\right)_{2} \mathrm{MgSi}_{2} \mathrm{O}_{7}$ : $\mathrm{Eu}^{2+}, \mathrm{Dy}^{3+}$ via Solid Solution for Use in Point-of-Care Diagnostics. ACS Appl. Mater. Interfaces 2016, 8, 26956-26963.

(9) Liao, S.; Ji, X.; Liu, Y.; Zhang, J. Highly Efficient and Thermally Stable Blue-Green $\left(\mathrm{Ba}_{0.8} \mathrm{Eu}_{0.2} \mathrm{O}\right)\left(\mathrm{Al}_{2} \mathrm{O}_{3}\right)_{4.575 \times(1+\mathrm{x})}$ Phosphor through Structural Modification. ACS Appl. Mater. Interfaces 2018, 10, 3906439073.

(10) Zu, Y.; Xi, J.; Li, L.; Dai, J.; Wang, S.; Yun, F.; Jiao, B.; Dong, H.; Hou, X.; Wu, Z. High-Brightness and Color-Tunable $\mathrm{FAPbBr}_{3}$ Perovskite Nanocrystals 2.0 Enable Ultrapure Green Luminescence for Achieving Recommendation 2020 Displays. ACS Appl. Mater. Interfaces 2020, 12, 2835-2841.

(11) Wang, L.; Xie, R.; Suehiro, T.; Takeda, T.; Hirosaki, N. DownConversion Nitride Materials for Solid State Lighting: Recent Advances and Perspectives. Chem. Rev. 2018, 118, 1951-2009.

(12) Terraschke, H.; Wickleder, C. UV, Blue, Green, Yellow, Red, and Small: Newest Developments on $\mathrm{Eu}^{2+}$ Doped Nanophosphors. Chem. Rev. 2015, 115, 11352-11378.

(13) Qin, X.; Liu, X.; Huang, W.; Bettinelli, M.; Liu, X. LanthanideActivated Phosphors Based on 4f-5d Optical Transitions: Theoretical and Experimental Aspects. Chem. Rev. 2017, 117, 4488-4527.

(14) Ueda, J.; Miyano, S.; Tanabe, S. Formation of Deep Electron Traps by $\mathrm{Yb}^{3+}$ Codoping Leads to Super-Long Persistent Luminescence in $\mathrm{Ce}^{3+}$-Doped Yttrium Aluminum Gallium Garnet Phosphors. ACS Appl. Mater. Interfaces 2018, 10, 20652-20660.

(15) Wang, Z.; Zhu, C. Y.; Yin, S. Y.; Wei, Z. W.; Zhang, J. H.; Fan, Y. N.; Jiang, J. J.; Pan, M.; Su, C. Y. A Metal-Organic Supramolecular Box as a Universal Reservoir of UV, WL, and NIR Light for LongPersistent Luminescence. Angew. Chem., Int. Ed. 2019, 58, 34813485.

(16) Gong, Z.; Zheng, W.; Gao, Y.; Huang, P.; Tu, D.; Li, R.; Wei, J.; Zhang, W.; Zhang, Y.; Chen, X. Full-Spectrum Persistent Luminescence Tuning Using All-Inorganic Perovskite Quantum Dots. Angew. Chem., Int. Ed. 2019, 58, 6943-6947.

(17) Zhu, Y.; Pang, Z.; Wang, J.; Ge, M.; Sun, S.; Hu, Z.; Zhai, J.; Gao, J.; Jiang, F. Effect of light conversion agent on luminous properties of a new down-converting material $\mathrm{SrAl}_{2} \mathrm{O}_{4}: \mathrm{Eu}^{2+}, \mathrm{Dy}^{3+} /$ light conversion agent. J. Rare Earths 2016, 34, 483-488.

(18) Chen, Z.; Zhu, Y.; Ge, M. Effect of red emitting fluorescent pigment on fluorescent color of $\mathrm{SrAl}_{2} \mathrm{O}_{4}: \mathrm{Eu}^{2+}, \mathrm{Dy}^{3+}$ phosphors. J. Rare Earths 2017, 35, 247-253.

(19) Merzlyakova, E.; Wolf, S.; Lebedkin, S.; Bayarjargal, L.; Neumeier, B. L.; Bartenbach, D.; Holzer, C.; Klopper, W.; Winkler, B.; Kappes, M.; et al. 18-Crown-6 Coordinated Metal Halides with Bright Luminescence and Nonlinear Optical Effects. J. Am. Chem. Soc. 2021, 143, 798-804.

(20) Yang, Q.; Cai, Y. Y.; Zhu, Z. Y.; Sun, L. X.; Choo, Y. S. L.; Zhang, Q. G.; Zhu, A. M.; Liu, Q. L. Multiple Enhancement Effects of Crown Ether in Tröger's Base Polymers on the Performance of Anion Exchange Membranes. ACS Appl. Mater. Interfaces 2020, 12, 2480624816.

(21) Han, X.; Han, Y.; Chen, C. Pagoda[4]arene andi-Pagoda[4] arene. J. Am. Chem. Soc. 2020, 142, 8262-8269.

(22) Liu, Y.; Wang, H.; Liu, P.; Zhu, H.; Shi, B.; Hong, X.; Huang, F. Azobenzene-Based Macrocyclic Arenes: Synthesis, Crystal Structures, and Light-Controlled Molecular Encapsulation and Release. Angew. Chem., Int. Ed. 2021, 60, 5766-5770.

(23) Hanayama, H.; Yamada, J.; Tomotsuka, I.; Harano, K.; Nakamura, E. Rim Binding of Cyclodextrins in Size-Sensitive Guest Recognition. J. Am. Chem. Soc. 2021, 5786-5792.

(24) Falaise, C.; Moussawi, M. A.; Floquet, S.; Abramov, P. A.; Sokolov, M. N.; Haouas, M.; Cadot, E. Probing Dynamic Library of Metal-Oxo Building Blocks with $\gamma$-Cyclodextrin. J. Am. Chem. Soc. 2018, 140, 11198-11201.

(25) Jin, H.; Yang, L.; Ahonen, M. J. R.; Schoenfisch, M. H. Nitric Oxide-Releasing Cyclodextrins. J. Am. Chem. Soc. 2018, 140, 1417814184 .

(26) Mako, T. L.; Racicot, J. M.; Levine, M. Supramolecular Luminescent Sensors. Chem. Rev. 2019, 119, 322-477.

(27) Xia, Y.; Chen, S.; Ni, X. White Light Emission from Cucurbituril-Based Host-Guest Interaction in the Solid State: New Function of the Macrocyclic Host. ACS Appl. Mater. Interfaces 2018, $10,13048-13052$.

(28) Dube, H.; Ams, M. R.; Rebek, J. Supramolecular Control of Fluorescence through Reversible Encapsulation. J. Am. Chem. Soc. 2010, 132, 9984-9985.

(29) Benson, C. R.; Kacenauskaite, L.; VanDenburgh, K. L.; Zhao, W.; Qiao, B.; Sadhukhan, T.; Pink, M.; Chen, J.; Borgi, S.; Chen, C.; 
et al. Plug-and-Play Optical Materials from Fluorescent Dyes and Macrocycles. Chem 2020, 6, 1978-1997.

(30) Frischmann, P. D.; Kunz, V.; Würthner, F. Bright Fluorescence and Host-Guest Sensing with a Nanoscale $\mathrm{M}_{4} \mathrm{~L}_{6}$ Tetrahedron Accessed by Self-Assembly of Zinc-Imine Chelate Vertices and Perylene Bisimide Edges. Angew. Chem., Int. Ed. 2015, 54, 72857289.

(31) Yamashina, M.; Sartin, M. M.; Sei, Y.; Akita, M.; Takeuchi, S.; Tahara, T.; Yoshizawa, M. Preparation of Highly Fluorescent HostGuest Complexes with Tunable Color upon Encapsulation. J. Am. Chem. Soc. 2015, 137, 9266-9269.

(32) Fan, C.; Wu, W.; Chruma, J. J.; Zhao, J.; Yang, C. Enhanced Triplet-Triplet Energy Transfer and Upconversion Fluorescence through Host-Guest Complexation. J. Am. Chem. Soc. 2016, 138, $15405-15412$.

(33) Saenger, W. Cyclodextrin Inclusion Compounds in Research and Industry. Angew. Chem. Int. Ed. 1980, 19, 344-362.

(34) Poór, M.; Zand, A.; Szente, L.; Lemli, B.; Kunsági-Máté, S. Interaction of $\alpha$ - and $\beta$-zearalenols with $\beta$-cyclodextrins. Molecules 2017, 22, No. 1910.

(35) Al-Soufi, W.; Reija, B.; Novo, M.; Felekyan, S.; Kühnemuth, R.; Seidel, C. A. M. Fluorescence Correlation Spectroscopy, a Tool to Investigate Supramolecular Dynamics: Inclusion Complexes of Pyronines with Cyclodextrin. J. Am. Chem. Soc. 2005, 127, 87758784.

(36) Song, S.; Chong, Y.; Fu, H.; Ning, X.; Shen, H.; Zhang, Z. HP$\beta$-CD Functionalized $\mathrm{Fe}_{3} \mathrm{O}_{4} / \mathrm{CNPs}$-Based Theranostic Nanoplatform for $\mathrm{pH} / \mathrm{NIR}$ Responsive Drug Release and MR/NIRFL ImagingGuided Synergetic Chemo/Photothermal Therapy of Tumor. ACS Appl. Mater. Interfaces 2018, 10, 33867-33878.

(37) Geng, Q.; Xie, J.; Wang, X.; Cai, M.; Ma, H.; Ni, H. Preparation and Characterization of Butachlor/(2-Hydroxypropyl)- $\beta$-cyclodextrin Inclusion Complex: Improve Soil Mobility and Herbicidal Activity and Decrease Fish Toxicity. J. Agric. Food Chem. 2018, 66, 1219812205 .

(38) Prochowicz, D.; Kornowicz, A.; Lewiński, J. Interactions of Native Cyclodextrins with Metal Ions and Inorganic Nanoparticles: Fertile Landscape for Chemistry and Materials Science. Chem. Rev. 2017, 117, 13461-13501.

(39) Clabau, F.; Rocquefelte, X.; Jobic, S.; Deniard, P.; Whangbo, M. H.; Garcia, A.; Le Mercier, T. Mechanism of Phosphorescence Appropriate for the Long-Lasting Phosphors $\mathrm{Eu}^{2+}$-Doped $\mathrm{SrAl}_{2} \mathrm{O}_{4}$ with Codopants $\mathrm{Dy}^{3+}$ and $\mathrm{B}^{3+}$. Chem. Mater. 2005, 17, 3904-3912.

(40) Yuan, C.; Jin, Z.; Xu, X. Inclusion complex of astaxanthin with hydroxypropyl- $\beta$-cyclodextrin: UV, FTIR, ${ }^{1} \mathrm{H}$ NMR and molecular modeling studies. Carbohydr. Polym. 2012, 89, 492-496.

(41) Yuan, C.; Jin, Z.; Xu, X.; Zhuang, H.; Shen, W. Preparation and stability of the inclusion complex of astaxanthin with hydroxypropyl$\beta$-cyclodextrin. Food Chem. 2008, 109, 264-268.

(42) Bakkialakshmi, S.; Menaka, T. Fluorescence enhancement of rhodamine $6 \mathrm{G}$ by forming inclusion complexes with $\beta$-cyclodextrin. $J$. Mol. Liq. 2011, 158, 117-123.

(43) Hamdi, H.; Abderrahim, R.; Meganem, F. Spectroscopic studies of inclusion complex of $\beta$-cyclodextrin and benzidine diammonium dipicrate. Spectrochim. Acta, Part A 2010, 75, 32-36.

(44) Ge, X.; He, J.; Qi, F.; Yang, Y.; Huang, Z.; Lu, R.; Huang, L. Inclusion complexation of chloropropham with $\beta$-cyclodextrin: Preparation, characterization and molecular modeling. Spectrochim. Acta, Part A 2011, 81, 397-403.

(45) Celebioglu, A.; Kayaci-Senirmak, F.; İpek, S.; Durgun, E.; Uyar, T. Polymer-free nanofibers from vanillin/cyclodextrin inclusion complexes: high thermal stability, enhanced solubility and antioxidant property. Food Funct. 2016, 7, 3141-3153.

(46) Periasamy, R.; Kothainayaki, S.; Rajamohan, R.; Sivakumar, K. Spectral investigation and characterization of host-guest inclusion complex of 4,4'-methylene-bis(2-chloroaniline) with beta-cyclodextrin. Carbohydr. Polym. 2014, 114, 558-566.

(47) Martínez, A.; Ortiz, M. C.; Garcia, F. J. Cyclodextrin-based multivalent glycodisplays: covalent and supramolecular conjugates to assess carbohydrate-protein interactions. Chem. Soc. Rev. 2013, 42, $4746-4773$.

(48) Wei, Z.; Gu, Z.; Arvapally, R. K.; Chen, Y.; McDougald, R. N.; Ivy, J. F.; Yakovenko, A. A.; Feng, D.; Omary, M. A.; Zhou, H. Rigidifying Fluorescent Linkers by Metal-Organic Framework Formation for Fluorescence Blue Shift and Quantum Yield Enhancement. J. Am. Chem. Soc. 2014, 136, 8269-8276.

(49) Liu, J.; Wang, N.; Yu, Y.; Yan, Y.; Zhang, H.; Li, J.; Yu, J. Carbon dots in zeolites: A new class of thermally activated delayed fluorescence materials with ultralong lifetimes. Sci. $A d v .2017,3$, No. e1603171.

(50) Szejtli, J. Introduction and General Overview of Cyclodextrin Chemistry. Chem. Rev. 1998, 98, 1743-1754.

(51) Berberan-Santos, M. N.; Choppinet, P.; Fedorov, A.; Jullien, L.; Valeur, B. Multichromophoric Cyclodextrins. 8. Dynamics of Homoand Heterotransfer of Excitation Energy in Inclusion Complexes with Fluorescent Dyes. J. Am. Chem. Soc. 2000, 122, 11876-11886.

(52) Takakusa, H.; Kikuchi, K.; Urano, Y.; Higuchi, T.; Nagano, T. Intramolecular Fluorescence Resonance Energy Transfer System with Coumarin Donor Included in $\beta$-Cyclodextrin. Anal. Chem. 2001, 73, 939-942.

(53) Martyn, T. A.; Moore, J. L.; Halterman, R. L.; Yip, W. T. Cucurbit[7]uril Induces Superior Probe Performance for SingleMolecule Detection. J. Am. Chem. Soc. 2007, 129, 10338-10339.

(54) Zeng, P.; Wei, X.; Yin, M.; Chen, Y. Investigation of the long afterglow mechanism in $\mathrm{SrAl}_{2} \mathrm{O}_{4}: \mathrm{Eu}^{2+} / \mathrm{Dy}^{3+}$ by optically stimulated luminescence and thermoluminescence. J. Lumin. 2018, 199, 400406.

(55) Yu, X.; Xu, X.; Qiu, J. Enhanced long persistence of $\mathrm{Sr}_{2} \mathrm{SnO}_{4}: \mathrm{Sm}^{3+}$ red phosphor by co-doping with Dy3+. Mater. Res. Bull. 2011, 46, 627-629.

(56) Wang, H.; Liang, X.; Liu, K.; Zhou, Q.; Chen, P.; Wang, J.; Li, J. Synthesis of $\mathrm{SrAl}_{2} \mathrm{O}_{4}: \mathrm{Eu}^{2+}$ phosphors co-doped with $\mathrm{Dy}^{3+}, \mathrm{Tb}^{3+}, \mathrm{Si}^{4+}$ and optimization of co-doping amount by response surface method. Opt. Mater. 2016, 53, 94-100.

(57) Kandpal, S. K.; Goundie, B.; Wright, J.; Pollock, R. A.; Mason, M. D.; Meulenberg, R. W. Investigation of the Emission Mechanism in Milled $\mathrm{SrAl}_{2} \mathrm{O}_{4}$ : Eu, Dy Using Optical and Synchrotron X-ray Spectroscopy. ACS Appl. Mater. Interfaces 2011, 3, 3482-3486.

(58) Zheng, L.; Zhu, Y.; Pang, Z.; Ge, M. Luminescence Properties of Composite Material $\mathrm{Sr}_{2} \mathrm{MgSi}_{2} \mathrm{O}_{7}: \mathrm{Eu}^{2+}, \mathrm{Dy}^{3+} /$ Light Conversion Agent with Multilayer Structure. In Journal of Rare Earths; Elsevier, 2020.

(59) Zhu, Y.; Ge, M. Study on the energy transfer efficiency from $\mathrm{SrAl}_{2} \mathrm{O}_{4}: \mathrm{Eu}^{2+}, \mathrm{Dy}^{3+}$ to light conversion agent of red-emitting phosphor: $\mathrm{SrAl}_{2} \mathrm{O}_{4}: \mathrm{Eu}^{2+}, \mathrm{Dy}^{3+} /$ light conversion agent. Mater. Lett. 2016, 182, 173-176.

(60) Bakkialakshmi, S.; Menaka, T. A study of the interaction between rhodamine $6 \mathrm{~g}$ and hydroxy propyl $\beta$-cyclodextrin by steady state fluorescence. Spectrochim. Acta, Part A 2011, 81, 8-13.

(61) Han, S.; Singh, K. C.; Cho, T.; Lee, H.; Jakhar, D.; Hulme, J. P.; Han, C.; Kim, J.; Chun, I.; Gwak, J. Preparation and characterization of long persistence strontium aluminate phosphor. J. Lumin. 2008, $128,301-305$. 